\title{
Preservice Teacher Understanding and Vision of how to Teach Biological Evolution
}

\author{
Louis S. Nadelson
}

Published online: 8 January 2009

(C) Springer Science + Business Media, LLC 2008

\begin{abstract}
The learning and teaching of biological evolution is conceptually challenging. To fully comprehend evolution, it is posited that individuals also need to understand the roles that the nature of science and situations of chance play in the process. The consistent detection of misconceptions of evolution suggests that new approaches to increasing understanding need to be explored. I predicted that preservice teachers' ideas for teaching biological evolution could be influenced by three brief web-based interventions, one focused on the common misconceptions of evolution, one on the nature of science, and one on situations of uncertainty in the context of evolution. An experimental group received a combination of the three web-based tutorials while a control group received the misconceptions and nature of science instruction and a time on task filler tutorial. Participants were directed to develop a lesson idea applying the knowledge they learned from the tutorials. The lesson ideas were examined for evidence of the influence of the web-based instruction, participant understanding and misconceptions of concepts, and their ideas about teaching evolution. The results of this study revealed that the participating preservice teachers held a wide range of conception and misconception of evolution, were somewhat influenced by the tutorials, and had an array of visions for teaching evolution. The outcomes support the need for further investigation into the multifaceted nature of preparing preservice teachers to teach evolution.
\end{abstract}

Keywords Preservice teacher - Biological evolution. Misconception - Nature of Science $\cdot$ Situations of uncertainty

\section{S. Nadelson $(\square)$}

Boise State University,

1910 University Drive,

Boise, ID 83725-1700, USA

e-mail: LouisNadelson@boisestate.edu

\section{Introduction}

One of the most misconceived and widely debated scientific phenomena is biological evolution (Alters and Alters 2001, Gallup 2008, Miller 1999). The misconceptions and controversy surrounding biological evolution can range from minor misunderstandings to complete theory rejection (Alters and Alters 2001, Dagher and Boujaoude 2005, Evans 2001, Mazur 2004, McComas 2006, Sadler 2005). Evolution misconceptions are common because everyday experiences are readily applied to explain seemingly related phenomenon (Driver et al. 1994, Tversky and Kahneman 1982). Some misconceptions of evolution may be difficult to detect and may not be exposed unless individuals are faced with situations that require them to apply their understanding (Chinn and Brewer 1998, Sinatra et al. 2003, Vosniadou 2003). This research investigated the influence of web-based tutorials on preservice teachers' knowledge of biological evolution by examining products of their visions for teaching the theory.

\section{Misconceptions and Evolution}

Scientific understanding of biological evolution is complex and multifaceted (Futuyma 2002, Gould 2002, Miller 1999); therefore it is not surprising that people may hold incomplete knowledge or misconceptions about the processes (Miller 1999). A common evolution misconception is to view the process as deterministic, with organisms aspiring to become more efficient, improved, or complex life forms (Alters and Alters 2001, McComas 2006, NAS 1998). The misconception may form by understanding societal goals of creating products that are faster, lighter, and more efficient and inferring that perspective toward 
nature and viewing evolution as a process trying to achieve similar developmental outcomes. The use of familiar experiences to explain seemingly similar situations may involve the application of the representativeness or availability heuristics that have been documented in a range of contexts (Tversky and Kahneman 1982).

The problem with holding misconceptions of biological evolution is that scientific literacy in the field of biology necessitates understanding the theory (Dobzhansky 1973). Comprehending societal issues such as genetic engineering, antibiotic-resistant bacteria, and deforestation, requires understanding evolutionary theory. Biological developments often require public involvement for policy decisions and therefore necessitate an informed citizenry. Holding misconceptions of evolution may impede the ability to develop effective policy related to biological developments. Further, misconceptions of evolutionary theory may hinder the ability to learn new concepts or may actually lead to the development of additional or more complex misconceptions (Alters 2004, McComas 2006, Miller 1999).

To promote meeting the goals of an informed citizenry, efforts by organizations such as the National Science Teacher Association (NSTA) (1997) have included biological evolution as a major component of their teacher preparation and science curriculum standards. Many state departments of education have responded likewise, establishing biological evolution as a big idea or thematic component of their science educational standards starting as early as the primary grades (Florida Department of Education 2008, Moore 2001). The integration of evolution concepts into the science standards in K-8 supports the necessity for all K-12 teachers to understand the foundational concepts. This suggests that acquiring knowledge of evolution should not be limited to secondary biology teachers but should also include primary and elementary teachers (NRC 2007).

\section{Situations of Chance and Evolution}

The depth and breadth of scientific research influencing evolutionary theory has produced a lengthy and complex description of the mechanisms and processes of evolution. Included in descriptions of biological evolution is the role of chance (Dawkins 1986, Gould 2002, Miller 1999). However, as Gould argues, chance is not well understood, particularly in the context of evolution. This suggests that a possible source of misconceptions of biological evolution may develop from the fallacious understanding of situations of chance (Garvin-Doxas and Klymkowsky 2008, Sadler 2005). The influence of chance on processes in evolution suggests that individuals may need to understand situations of chance to accurately conceptualize evolution. However, because situations of chance are also beset with misconceptions (Nickerson 2004, Shaughnessy 2003), resolving the misconceptions of evolution that involves chance may be extremely challenging.

The development and retention of misconceptions of situations of chance may be due to an inherent tendency for individuals to interpret chance phenomena in terms of cause and effect or as self-correcting (Tversky and Kahneman 1982, Wolpert 2007). These perspectives of chance lead to misconceptions because, when applied to evolution, they surmise a cause and effect process that is self-correcting. Some documented misconceptions of evolutionary biology may be represented by the same heuristics associated with misconceptions of situations of chance (Sadler 2005). The link between evolution and situations of chance indicate that there is a need to resolve the misconceptions of both to accurately understand biological evolution.

\section{The Nature of Science and Evolution}

It is argued that learners must understand the nature of science to appropriately conceptualize evolution (McComas 2006, NRC 1996). Therefore, like correct knowledge of situations of chance, accurate understanding of the nature of science is considered to be essential for understanding biological evolution (NRC 1996, AAAS 1993). Yet, similar to the conditions found in conceptions of situations of chance, many people hold predictable and readily identified misconceptions about the nature of science (Abd-ElKhalick and Akerson 2004, Cooper 2002, McComas 1998, Scharmann et al. 2005).

According to McComas (1998), understanding the knowledge construct of theory is a nature of science misconception that is frequently associated with misconceptions of biological evolution. Used on a daily basis, the term theory typically represents ideas, conjectures, anticipated outcomes, or unsubstantiated knowledge claims. However, in science, the term theory is used to represent well-developed, scientifically-accepted, evidence-based explanations (McComas 1998, NRC 1996). However, it is common for people to incorrectly apply the everyday use of theory to misconstrue evolutionary theory as a tentative prediction lacking reliability. The frequently argued phase, "evolution is only a theory and not a fact," reflects the application of a nature of science misconception to reinforce a misconception of biological evolution (Miller 2008).

The misconceptions of biology, situations of chance, and the nature of science can combine to significantly hinder learning and understanding evolutionary theory. Given that most teachers experience the same levels of science education as the general public, it is expected that they too will hold these same misconceptions. However, as science education standards shift to include teaching evolution throughout the K-12 curriculum, it is imperative that all teachers are adequately prepared to teach the theory. 
Teachers, Misconceptions, and Evolution

There is an abundance of curriculum materials available for teaching and learning biological evolution (NRC 1996, 2007), and yet a significant percentage of the public continues to reject the validity of the theory (Gallup 2008). This suggests that we need empirical evidence to determine the effectiveness of instructional approaches for teaching and learning evolution to resolve misconceptions and increase theory acceptance. Arguably, the most critical population for providing effective curriculum that increases knowledge of evolution while addressing misconceptions is K-12 teachers (FLDOE 2008, NAS 1998, NRC 1996, 2007, NSTA 1997). Misconceptions have been found to be held by novices through experts (Palmquist and Finley 1997, Tversky and Kahneman 1982); therefore, it is anticipated that teachers also hold a range of misconceptions (Kikas 2004).

Teachers, like others who hold beliefs and conceptions very tightly, may not be prepared to consider alternative explanations or be motivated to engage in situations that challenge their perspectives (Hill 2004, Hoy et al. 2006, Pajares 1992). Jarvis et al. (2003) elucidate on the problem with teachers holding content misconceptions and lacking impetus to explore alternative perspectives as they report that educators are nearly certain to teach their misconceptions to their students. There is evidence indicating that many science misconceptions may actually have been taught by teachers to their students (Alters and Nelson 2002, Driver et al. 1994, Fisher 2004), which makes evident that misconceptions are, in part, perpetuated by teachers (Haidar 1997, Lawrenz 1986). This suggests that when teachers have incomplete science knowledge or hold science misconceptions, or both, they may critically impede student conceptual development of scientific explanations (Crawford et al. 2005, Fisher 2004, Jarvis et al. 2003, Kikas 2004).

The development of teacher knowledge of the concepts requires the assimilation of the content, as well as an awareness of common misconceptions (Darling-Hammond and Bransford 2005, Shulman 1987). Teachers' understanding of content is nearly directly correlated with their education (Hoy et al. 2006, Pajares 1992), which implies that teachers may be constrained to teaching the content they were taught (Alters and Nelson 2002, Deemer 2004, Llinares and Krainer 2006). This suggests that it is crucial to utilize empirically supported instruction and curriculum to effectively address teachers' evolution misconceptions and promote the development of accurate evolution knowledge prior to their entering service.

Engaging preservice teachers in situations in which they communicate their vision for teaching evolution concepts is potentially fruitful for determining their knowledge, perceptions, and misconceptions of evolutionary biology. The reliance on instructional materials to increase preservice teachers' awareness of evolution misconceptions and understanding of evolutionary theory fundamentals provides justification for gathering empirical evidence to assess curriculum effectiveness (NAS 1998, 2008). This research project explored the influence of the NSF-sponsored Understanding Evolution web site (University of California Museum of Paleontology 2006) and other web-based materials on undergraduate preservice teachers, misconceptions and knowledge of evolution through an assessment of their visions for teaching evolution after completing a series of web-based tutorials.

\section{Research Goals, Questions, and Hypothesis}

Even though the development of three research questions may be interpreted as extremely ambitious for a single investigation, I argue that my questions are inextricably related. Further, I argue that how teachers are taught, the way that they teach, what they teach, and the misconceptions that they hold, should not be considered independently. Each of these processes is influenced by the others. Therefore, when examining the influence of instructional interventions on teacher content knowledge, one must also examine the influence on teachers' perspectives of pedagogy, and their misconceptions.

The first goal of my investigation was to determine the effectiveness of using lesson ideas (a condensed and informal lesson plan) as evidence of preservice teachers' understanding and vision of teaching evolution. The second goal of my study was to diagnose preservice teachers' conceptions and misconceptions of evolution, the nature of science, and situations of uncertainty through the examination of their visions for teaching biological evolution. The third goal of my research was to determine the influence of the components of Understanding Evolution (UCMP 2006) and my situations of uncertainty tutorial on preservice teachers, using the lesson ideas as sources of evidence.

My study goals lead to the development of these research questions:

1). What can lesson ideas tell us about how preservice teachers envision teaching evolution?

2). What can preservice teacher lesson ideas for teaching evolution tell us about their understanding and misconceptions of biological evolution?

3). Can preservice teacher lesson ideas for teaching evolution provide evidence for the influence of a relatively brief instructional intervention?

The open-ended structure of the lesson ideas allowed for freedom of expression, which was anticipated to effectively capture participants' vision and understanding for teaching evolution. Therefore, I hypothesized that the lesson ideas 
Table 1 The demographic measures for the control and experimental groups

\begin{tabular}{|c|c|c|c|c|c|c|c|c|}
\hline Group & Number of participants & Age & & Years of college & Gender & & Ethnicity & \\
\hline \multirow[t]{4}{*}{ Experimental } & 34 & $18-20$ & 8 & 2.03 & Female & 27 & African American & 4 \\
\hline & & $21-25$ & 20 & & Male & 7 & Asian & 3 \\
\hline & & $26-35$ & 5 & & & & Latino & 3 \\
\hline & & $36-45$ & 1 & & & & Caucasian & 23 \\
\hline \multirow[t]{4}{*}{ Control } & 34 & $18-20$ & 11 & 1.88 & & & African American & 2 \\
\hline & & $21-25$ & 17 & & Female & 28 & Asian & 3 \\
\hline & & $26-35$ & 4 & & Male & 6 & Latino & 2 \\
\hline & & $46+$ & 2 & & & & Caucasian & 24 \\
\hline
\end{tabular}

would be an effective method for gathering evidence of the participating preservice teachers' knowledge, conceptions, and misconceptions about evolution.

The association of concepts between evolutionary theory, the nature of science, and situations of chance suggests that instruction is required for all to resolve evolution misconceptions. Therefore, I hypothesized that combined instructional content of these areas would increase participant understanding of the concepts and development of accurate evolution conceptions, while resolving their misconceptions. Finally, I hypothesized that the addition of the situations of chance instruction would increase the experimental group participants' understanding of the importance of chance in the processes in evolution which would be reflected in their lesson ideas.

\section{Methods}

\section{Participants}

The participants in my study were a convenience sample of K-12 preservice teachers recruited from a departmental undergraduate research subject pool in a large urban university in southwest United States. The participants were randomly assigned to either the control $(N=34)$ or experi- mental group $(N=34)$. The participants were not aware of the group to which they had been assigned, which increased the likelihood of more accurate representative sampling.

General demographic data such as age, years of post secondary education, and ethnicity were collected from the participants. The two groups were nearly equal in their distribution of participant demographics (see Table 1).

The number of science and mathematics courses, the intended grade level of service, and participant college major were also found to be nearly equally distributed between the two groups (see Table 2).

A total of six students from the experimental and control groups indicated that they were pursuing certification in mathematics or science, which may differentially influence their perspectives of how evolution should be taught. Therefore, the coding results of the lesson ideas created by participants majoring in science or mathematics were reported using an upper case $\mathrm{M}$ to designate mathematics major and an upper case $\mathrm{S}$ to denote science major.

\section{Instructional Tutorials}

A total of four web-based tutorials were used in this study. Two tutorials, the misconceptions of evolution and nature of science, were obtained from the Understanding Evolution (UCMP 2006) website (http://evolution.berkeley.edu/).

Table 2 The measures of science and mathematics courses, intended grade level of service, and college major for the experimental and control groups

\begin{tabular}{|c|c|c|c|c|c|c|c|c|c|}
\hline Subject area & Number of courses & Exper. & Cont. & Major & Exper. & Cont. & Grade level of service & Exper. & Cont. \\
\hline \multirow[t]{5}{*}{ Science } & 1 & 10 & 11 & English & 2 & 0 & $\mathrm{k}-2$ & 11 & 12 \\
\hline & 2 & 13 & 8 & Fine Arts & 1 & 2 & $3-5$ & 10 & 7 \\
\hline & 3 & 7 & 12 & Math & 1 & 3 & $6-8$ & 2 & 5 \\
\hline & 4 & 3 & 1 & Science & 2 & 0 & $9-12$ & 11 & 10 \\
\hline & 6 & 1 & 2 & Social Studies & 4 & 2 & & & \\
\hline \multirow[t]{5}{*}{ Math } & 1 & 7 & 11 & Education & 24 & 25 & & & \\
\hline & 2 & 11 & 13 & Health/PE/Careers & 0 & 1 & & & \\
\hline & 3 & 10 & 7 & Performing Arts & 0 & 1 & & & \\
\hline & 4 & 4 & 1 & & & & & & \\
\hline & 5 & 2 & 2 & & & & & & \\
\hline
\end{tabular}


I assembled the other two tutorials, situations of chance and a filler Travels of Charles Darwin from publicly available materials. Appendix 1 contains screen shots from the four tutorials.

Evolution Misconceptions and Nature of Science The webbased tutorials in biological evolution misconceptions and the nature of science were extracted from the NSF-funded Understanding Evolution tutorials (UCMP 2006). Several different evolution themes are presented and discussed in the Understanding Evolution tutorials; however, I specifically limited the participants' interaction to the misconceptions of evolution and the nature of science tutorials. I utilized the 23 pages from the Understanding Evolution website that focus on evolution misconceptions. The nature of science intervention used all 11 pages of Understanding Evolution that presented this content. Each web page combined about 150 to 200 words of content with supporting graphics to teach a specific concept. The University of California Museum of Paleontology granted permission for me to download parts of their web site to a local file server. By restricted access to the web pages from a local file server, I was able to monitor and regulate participant interaction with the instructional materials.

Situations of Chance I developed a series of five linked web pages to teach situations of chance concepts in the context of evolution using public domain content, graphics, and animation applets. To conform to the design of Understanding Evolution, I limited the text of each page to about 200 words and included corresponding graphics and animation applets. This tutorial presented situations of chance concepts such as variability and chance distributions in perspectives of biological evolution using five linked pages. Again, to monitor and regulate participant access, this tutorial was placed on the same local file server as the Understanding Evolution tutorials.

Filler Tutorial A filler web-based tutorial was developed to be administered to the control group in place of the situations of chance tutorial. This was done to assure equal time on task by providing both the control and experimental groups with relatively the same amount of content to read and comprehend. This tutorial is similar to the length (five pages) and format (combining graphics and about 200 words of text per page) as the situation of chance tutorial, but focused on the life and travels of Charles Darwin. I selected the life and travels of Charles Darwin because I anticipated it would not increase knowledge or decrease misconceptions of evolution, but was related to the general theme of the other tutorials so participants would remain engaged and complete the tutorial.
Experimental and Control Interventions

Both the experimental and control group received the Understanding Evolution (UCMP 2006) misconceptions and nature of science tutorials. However, the experimental group also received the situations of uncertainty tutorial, while the control group received the filler Life and Travels of Charles Darwin tutorial. This assured both groups had relatively the same time on task that was required to complete the three tutorials. Both sets of tutorials took approximately $30 \mathrm{~min}$ to complete.

\section{Data Collection}

To determine the influence of the web-based instruction on the participating preservice teachers' evolution knowledge, they were asked to develop a lesson idea based on the tutorials they read. The lesson idea, which was essentially a mini lesson plan, provided the participants with the opportunity to communicate their vision for teaching evolution. They were instructed to develop lessons for a desired grade level or content area (see Appendix 2 for the Lesson Idea Template). In the lesson ideas, participants communicated their targeted age group, content/subject area, title of the lesson, lesson goals, description of lesson activities, and an assessment plan. Immediately following the interaction with the tutorials, the participants were directed to a half-page lesson plan template which was accessed and completed using the Internet-based Zoomerang survey website. The participants completed their lessons in approximately 10-15 min. Once submitted, the completed lesson ideas where securely stored on the Zoomerang website and then downloaded to a local computer for analysis.

\section{Analysis}

\section{Lesson Idea Coding}

The lesson ideas were coded using a priori and emergent qualitative techniques (Cresswell 2003, Miles and Huberman 1994). My initial analysis focused on classifying the lessons into topical categories, such as evolution, nature of science, or situations of uncertainty. Once categorized, a secondary analysis was conducted to detect the presence of correct conceptions and misconceptions. Given the unique and incongruent occurrences of misconceptions, I did not classify them but instead identified and discussed them as they were detected within my analysis. A similar approach was used to expose evidence of participant transfer of tutorial content to their visions for teaching evolution. 
Table 3 The major lesson idea themes, codings, and relative frequencies of occurrence

\begin{tabular}{llcc}
\hline Major theme & Content coding/terms & $\begin{array}{c}\text { Control group } \\
\text { Number of lessons }\end{array}$ & $\begin{array}{c}\text { Experimental group } \\
\text { Number of lessons }\end{array}$ \\
\hline The Theory of Evolution & $\begin{array}{l}\text { Evolve, Natural Selection, Fossils, } \\
\text { Finches Adaptation, Species, Diversity/Different }\end{array}$ & 18 & 19 \\
Evolution and NOS & Theory, Acceptance, Religion, Proof/Evidence & 19 & 17 \\
Evolution and chance & Change With Time, Situation of Uncertainty, & 5 & 7 \\
& Chance, Distribution, Variation, Mutation & & \\
\hline
\end{tabular}

I used comparative analysis (Miles and Huberman 1994) as the theoretical framework. The combination of a priori and emergent coding used in the analysis was consistent with the accepted procedures and theoretical approaches typified by a comparative analysis of qualitative data. I selected the a priori codings to expose participant utilization and application of key terms related to the three main instructional concepts. I searched for language related to the biological evolution. I selected a priori coding terms such as adaptation, evolution, and natural selection. I applied a consistent approach for situations of chance, coding for key terms such as probability, variation, uncertainty, and chance. This approach was also applied to the coding for the nature of science, in which I used a priori codes such as evidence, theory, and acceptance (See Table 3).

To clarify my coding process, I have provided the following example. This is the lesson idea teaching activity described by subject 3510 (an education major):

"Look at a specific area of the globe. Choose a species of animal and move it to a remote area across the globe. Figure the changes that would occur within 200 years when the animal has new climate and food." (Subject 3510)

I determined that the primary theme of this lesson idea was to teach students about natural selection. I came to this conclusion based on the use of the words "species" and "change" combined with the inferences to time and new environmental conditions. This passage also reflects the misconception that noticeable changes within a species can occur when placed in a new environment, and changes will be detectable in a relatively short period of time. However, there was no perceivable evidence of the application of the instructional interventions.

\section{Results}

The major lesson idea themes, corresponding codings, and relative frequencies of occurrence within each group are presented in Table 3. It is important to note that the total of the major theme frequencies exceeds the sample sizes $(N=$ 34 for each group) because some of the lesson ideas equally communicated two major themes and therefore were included into the frequency count of both. I analyzed the lesson plans of the control group first to develop a baseline which I then used to compare and contrast with the experimental group data. The analysis is presented by a major theme with the data from the control group discussed first, followed by the experimental group.

\section{Evolutionary Theory-Control Group}

The content analysis of the control group's lesson ideas revealed that almost half of the participants focused the majority of their content on some aspect of the theory of evolution. Using the theory of evolution major theme codes, such as "natural selection" and "adaptation," I exposed several lesson ideas that reflected intent to teach the scientific understanding of evolution. The utilization of the evolution content in the lesson ideas indicated awareness of the importance of concept relationship of these processes associated with the theory. For example, this lesson idea of subject 5312 focused on adaptation and alludes to natural selection:

"Students will learn about certain animals environments, their adaptive characteristics to those environments and create their own explanation for how those animals may have adapted to survive. Another aspect of this lesson would be to have students explore concepts of competition and to relate this to humans." (Subject 5312)

The following lesson idea excerpts provide evidence of both a focus on evolutionary theory and the influence of the tutorials. These two data from the control group lesson ideas typify the variety of responses that contained an evolutionary theory theme:

"I would definitely have them read the readings you provided us on how the theory of evolution is believed to work and how different groups feel about it." (Subject 6598) 
"For first graders I would guide them along a watered down version of the evolution theory so they could grasp it as best as possible. I would also include the stories about the Galapagos finches because that would really capture their attention. I might also provide worksheets or coloring sheets of the finches and evolution human figures to provide creativity to the lesson program.” (Subject 8805)

Subject 6598 conveys a sense of instructional value for the study tutorial, considering them as a useful resource for lesson teaching evolution. The integration of the Galapagos finch research into a lesson to capture students' attention by Subject 8805 provides evidence for the influence of the Understanding Evolution nature of science tutorial.

Several of the control group lesson ideas that addressed the evolutionary theory major theme also communicated misconceptions. For example, this subsequent passage drafted by Subject 4901 hints that natural selection is independent of biological evolution. This participant may be holding the misconception that natural selection and evolution are unrelated processes:

"Study the differences between evolution and natural selection. Allow the students to choose an animal to study and research.” (Subject 4901)

This lesson idea excerpt drawn from product developed by Subject 9391 reflects the misconception that, in the theory of evolution, natural selection involves organisms fighting to be best:

"Students would probably watch a video on natural selection, then we would look at some different animals in different habitats that fight to be the best. They would do some sort of activity where they would create their own species and explain what the species' strengths and weaknesses were and as a class as a whole we would play a game to see which animal comes out on top as the strongest." (Subject 9391)

The Understanding Evolution tutorial explicitly addressed misconceptions of evolution, yet they persisted and were detectable in several of the lessons. Evidence of misconceptions of evolution and natural selection persisted and were found to be present in a variety of forms. This passage makes evident that participants may have incomplete or fragmented knowledge of evolution, as this participant wrote:

"Students will understand the different kinds of evolution that occur in humans." (Subject 6685-Math Major)

Subject 6685 may be confusing the various mechanisms of evolution as being different kinds of evolution, may be considering including Lamarckian views, which may not view evolution as a processes of inextricably related variables. The persistence of misconceptions of evolution following the tutorial that explicitly addressed many of these topics makes evident there was limited instructional effectiveness. This suggests that participants viewed the Understanding Evolution misconceptions and nature of science tutorials as useful sources of ideas for teaching evolution concepts, but the instruction did not guarantee resolution of misconceptions or increased understanding or acceptance of the theory.

\section{Evolutionary Theory-Experimental Group}

There were notable similarities between the experimental group and control group participants' evolution theory lesson ideas. As with the control group, approximately half of the 34 experimental group's lesson ideas explicitly addressed evolutionary theory as their major theme. The extracts from the following lesson ideas are representative of experimental group products that focused on evolutionary theory as a major theme:

"I would test them to see if they understand what evolution is and how scientists came about with the theory of evolution." (Subject 1942)

"Teach the student about the theory of evolution, when it started off and the life span of our existence." (Subject 0037)

Although much of the details of these participants' perspectives is not provided, it is apparent that both view evolution theory as developing and have explanatory merit. This concept is covered extensively in the Understanding Evolution tutorials and seems to have been effectively applied in this participant's instructional vision. However, the extent of the influence of the interventions on participants' perspectives of the theory of evolution is difficult to precisely determine from these particular lesson proposals.

Analysis also made evident that some participants continued to hold theory of evolution misconceptions and attempted to integrate these perspectives with tutorial content in their lesson ideas. Some participants developed lesson ideas that applied alternative conceptions along with scientifically accepted perspectives of the theory of evolution. In several of these lesson ideas, the participants' application of misconceptions eclipsed attempts to integrate scientifically accepted perspectives. For example, in Subject 1641 's lesson idea, he communicated that it is possible to identify and teach a creation date of an organism, which seems to obscure his attempt to teach speciation:

"Students will have the option of choosing a prehistoric animal or present day animal of their choice. They will then have to draw the animal, list the type of 
environment it lived or lives in, and the approximate date of its creation/discovery". (Subject 1641)

The numerous lesson ideas that focused on evolutionary theory as a major theme reflect participant attention to the salience of the topics for teaching evolution, which one may consider to be stating the obvious. However, over half of the participants did not include the discussion of evolutionary theory as a major theme, which makes evident the multiple perspectives of how evolution should be taught. Analysis also revealed the integration of misconceptions of evolution into the lesson ideas within the experimental group in ways similar to the control group. The persistence and application of alternative conceptions in visions for teaching evolution makes evident the robust nature of misconceptions.

\section{Evolution and the Nature of Science-Control Group}

Coding of the lesson ideas for nature of science using codes such as "theory" and "proof" or "evidence" reveal approximately half of the participants focused on this as a major theme in their plans for teaching evolution. Dominating these lesson plans are epistemological issues related to the reliability and validity of evidence and support for the theory of evolution. This suggested that the processes by which science works was as important to the group as evolution content knowledge.

The large number of lesson ideas that focused on evolution and the nature of science may be due to the Understanding Evolution nature of science tutorial and the discussion of related issues in the misconceptions tutorial. The integration of a range of religious perspectives dominated the nature of science lesson ideas. Participant 6132 created a lesson idea for teaching science and religion as two distinct ways of knowing. The lesson idea developed by Subject 5277 reflects a vision for teaching a clear distinction between understanding the theories of science and the belief of religion. The lesson ideas that recognized science and religion as separate ways of knowing were similar to these:

"Inform students of evolutionary theory and explain its relation to other sciences, as well as it's independence from moral and religious ideas." (Subject 6132)

"Explain that this is science and not total truth. However, there is significant amount of evidence that proves that at least part of the theory of evolution is correct... Do not talk more about religion, your main focus here is science." (Subject 5277)

Some participants' nature of science lesson ideas revealed attempts to validate approaches that compare science and religious perspectives as equally valid explanations of evolution. Several related misconceptions of the nature of science were communicated in the lesson ideas, including perspectives that suggest that theories are tentative scientific schemes for explaining evolution with limited credibility. The lesson idea developed by Subject 9766 included the common argument that evolution should be taught "only as a theory" which is accompanied by "not everybody believes in evolution." This suggests that people do not believe in evolution because it is a theory, which blurs the epistemic distinction between knowledge and acceptance. The following lesson ideas represent the range of responses that address the ideologies of both religion and science:

"Keeping in mind that not everyone believes in evolution, I would teach this lesson only as a theory. I would however show the different physical evolutionary changes that man has gone through." (Subject 9766)

"Teacher: Discuss with students the different ideas of evolution-biblical and scientific.

Students: Discuss with each other which theory they believe in. Based on their choice, the students will write and draw what they learned and how they understand evolution.” (Subject 7946)

In their efforts to focus on the nature of science for teaching evolution, the participants' structure of scientific knowledge was a major theme. Several of the control groups' lesson ideas conveyed misconceptions of the nature of science by communicating the desire to teach scientific and religious perspectives as equally valid. The variety of lesson ideas focusing on the major theme of evolution and the nature of science revealed the variable influence that my study tutorials had on decreasing misconceptions of the nature of science in the context of evolution.

\section{Evolution and the Nature of Science-Experimental Group}

Similar to the control group, about half of the experimental group chose to focus on the nature of science as a major theme for their lesson ideas. Also, equivalent to the control group, several of the experimental group participants developed lesson ideas that conveyed an understanding that the theory of evolution was developed over time. In the lesson idea developed by Subject 6268, it is apparent that there is some acknowledgement of the development of the theory of evolution. This suggests that this participant had awareness that the theory developed over time:

"To track the origins of the theory of evolution and how the ideas themselves have evolved." (Subject 6268)

Comparable to the control group participants, the preservice teachers in the experimental group also communicated misconceptions, but not to the same extent. In the experimental group, there were fewer 
lesson ideas developed that were seeking to validate religious perspectives as equivalent to evolutionary theory. Most of the experimental group lesson ideas that included religious references sought to teach its epistemological differences to science. Lessons conveying science and religion as two distinct ways of knowing were similar to the following;

"Students will be able to know the differences and similarities between evolutionary science and religious dogmas. Students will work in groups of four (4). They will read through small, basic articles depicting similarities and differences in science and religion." (Subject 5900)

Several other experimental group participants developed lessons equivalent to Subject 5900. These lessons reflected awareness of the similarities and differences between religion and science and recognized the importance of teaching the distinction in the context of evolution. The consistency between the content of these lesson ideas and the tutorials provided evidence that indicates that the interventions influenced participants' understanding of the ontological and epistemological differences between the two ways of knowing.

Subject 2446 developed a plan for teaching the notion that people can hold theories that evolution does not exist. This seems to be analogous to the nature of science misconception in which individuals conflate the everyday use of the term theory with the application of the term within science. However, unlike the expression of similar misconceptions from the control group, there does not appear to be any detectable religious influence in this lesson idea. The participant's passage suggests he views theories as tentative ideas and not as evidence-based explanations. Subject 2446 wrote:

"The students will understand the definition of evolution and understand the process of evolution as well as the opposed theory that evolution does not exist." (Subject 2446)

Consistent with the control group, several of the experimental group participants developed lesson ideas that conveyed an understanding of scientific perspective of the nature of science. However, fewer participants communicated misconceptions of the nature of science concepts and did not conflate religious and scientific views in their lessons. The integration of content similar to that found in the tutorials provides further evidence for the influence of the intervention on the participants' knowledge and understanding of the theory of evolution.

\section{Evolution and Situations of Chance-Control Group}

The control group participants did not receive the situations of chance tutorial. Therefore, there was no expectation that they would develop lesson ideas that contained reference to the tutorial subject matter. Some of the control group participants did develop lesson ideas that included key words that were identified in the coding for situations of chance (time, mutations). This suggests that they had prior knowledge of these concepts and some awareness of their importance to teaching evolution. The prior knowledge of the control group maybe also inferred to the experimental group. The control group lesson ideas that were coded and categorized into the major theme of evolution and situations of chance only marginally addressed this topic.

\section{Evolution and Situations of Chance-Experimental Group}

Since the experimental group received the situations of uncertainty tutorial, there was an expectation that several of these participants would incorporate aspects of this major theme into their lesson ideas. This tutorial included a discussion of how variations of organisms can increase over extended periods of time. Utilizing this idea, four experimental group participants developed lesson ideas that emphasized the use of timelines to teach evolution. The content of the lesson ideas that included timelines suggested that the participants were intending to use the construct as a method for teaching about importance of time in the process of evolution. These participants producing activities similar to these:

"Watch a tadpole go through its changing in order to allow the students to observe this foreign idea I am placing before them. Compare the evolutionary theory to that, making sure to explain that this is actually something that happens over a vast amount of time and is not as observable as the tadpoles change." (Subject 5987)

"A PowerPoint of a timeline could be used for this lesson. Each animal, starting with the oldest, such as Dinosaurs, Saber tooth tigers, the platypus etc, would have a designated slide with a picture and description, along with the time line. This would continue until present day animals." (Subject 1641)

The emphasis on time in these lesson ideas reflects an understanding of the temporal attributes of biological evolution. The situation of uncertainty tutorial placed emphasis upon the role that time plays in the evolutionary process, which may account for the inclusion of time into some of the experimental groups' lesson ideas. This would also explain the lack of emphasis on time or the application of time lines in the control groups' lesson ideas.

Similar to the approach taken by Subject 1434, the experimental group participants that did include content from the situations of chance tutorial only hinted at utilizing the stochastic concepts to teach evolution. Subject 1434 applied the instructional presentation of finch beak size, which was 
used to discuss variation distribution within a species. The inclusion of this content provided some evidence for the influence of the tutorial. Subject 1434 wrote:

\section{"1. Research different Finch beaks and how they have evolved}

\section{Compare/contrast different sizes}

\section{Explain why the beaks are different" (Subject 1434)}

The perceivable differences between the control and experimental groups, inclusion of content addressing timelines, sizes of beaks, and mutations, is most likely attributed to the divergent interaction with the situations of chance tutorial by the groups. There is some evidence that the inclusion of situations of chance enhanced the experimental groups' understanding and perspective of evolution. However, the lack of stochastic content explicitly being explored in the lesson ideas makes it difficult to determine the extent of the influence on their conceptions of the role chance plays in evolution.

\section{Other Results-Both Groups}

As I was coding the lesson ideas for both groups for the three major evolution themes associated with the study tutorials, it became apparent that many participants integrated prior experiences such as lab activities, field trips, books, and museum visits, into the visions for teaching evolution. Like the occurrence of misconceptions, there was no perceivable pattern for these perspectives, and therefore, I did not record frequencies or bring attention to the associated data. The participants' incorporation of prior experience indicates that they were seeking additional relevant experiences to make their lesson ideas more effective.

Within the control and experimental groups were four math majors and two science majors. An examination of their lesson ideas did not reveal data that was unlike many of the other participants. The nature of science misconception questioning the validity of a scientific theory was detected in the lesson ideas presented by one of the math majors and one of the science majors. This suggests that additional course work required of science and mathematics majors may not have addressed this specific concept. Given the relatively small sample of mathematics and science majors, this outcome should be considered tentatively and kept in perspective.

\section{Discussion}

Through the use of the lesson idea methodology, I was able to document and empirically report preservice teachers' accurate conceptions, misconceptions, and visions for teaching evolution. Some of the lesson ideas reflected the current scientific perspectives of evolution, others communicated common misconceptions, and some conveyed a mixture of both. Although the lesson ideas provided limited the space for participant communication, the format did allow for freedom of expression, which proved to be an effective approach for gaining insight into the preservice teachers' perspectives of evolution. Most likely, this data would not have been exposed using survey instruments or other forced response instruments.

The lesson ideas provided evidence indicating that it was possible to influence preservice teacher perspectives for teaching evolution, the nature of science, and situations of uncertainty concepts with a rather brief intervention. I had anticipated that the lesson ideas would reflect a higher degree of integration of instructional materials due to the focused content and the engaging format of the tutorials. The content analysis of the lesson ideas exposed evidence for varying degrees of tutorial influence on participants' visions for teaching evolution. Perhaps if the tutorials were associated with additional instructional activities that required deeper levels of engagement, such as discussion of concepts, there would have been increased evidence for the integration of the content into the lesson ideas.

I also anticipated that several of the participants in the experimental group would develop evolution lesson ideas integrating situations of uncertainty. However, the experimental group participants failed to integrate situations of uncertainty concepts into their lesson ideas in a manner that resulted in detectable assimilation or comprehension of the content. This is reflective of the position of Gould (2002), who argued that there are significant levels of prior knowledge required for comprehending the relationship between uncertainty and evolution. The probable limited prior knowledge of situations of uncertainty of my participants may have constrained their ability to effectively integrate the content into their visions for teaching evolution. This is consistent with other research that reports that limited knowledge of stochastics impedes the ability to apply situations of uncertainty toward understanding and communicating about evolution (Garvin-Doxas and Klymkowsky 2008, Sadler 2005). Therefore, it is likely that a more intensive instructional intervention may be required to effect preservice teacher comprehension of the relationship between uncertainty and evolution, so they may effectively apply the concepts in their science curriculum and instruction.

The many occurrences of evidence for the integration of the nature of science and biological evolution concepts suggest that it may be easier to grasp and apply the relationship between these concepts than with uncertainty and evolution. About half of the control group and experimental group lesson ideas where categorized into 
the nature of science and evolution major theme. I partially attribute this emphasis to the Understanding Evolution nature of science and misconceptions of evolution tutorials. It was also possible that many of the participants had some background knowledge of how science works that increased their attention to and eased their integration of the nature of science content.

Evidence indicated that the participants continued to hold and envisioned teaching misconceptions of evolution and the nature of science, even some concepts that were addressed in depth in the tutorials. This provides further verification for the robust nature of misconceptions. Empirical evidence supporting preservice teachers' retention of misconceptions suggests that there is potential for these views to be taught to future students (Fisher 2004). The exposure of misconceptions provides credence for the necessity of assessing preservice teachers' misconceptions of evolution (and related topics) and addressing them prior to service (Hoy et al. 2006).

My results revealed that some of the participants lacked acceptance of evolution. The lack of acceptance for evolution was manifested by the participants in their lesson ideas that proposed to teach the religious perspective of creationism as an equally acceptable explanation for the origin of species. Further, there were several occurrences of teaching evolution as "only a theory." Even after exposure to the tutorials that address this misconception in depth, these participants retained the notion that a theory is a tentative explanation (McComas 1998). The lack of understanding about the structure of scientific theories could explain why some participants indicated that they were unsure about the evidence supporting evolutionary theory and proposed teaching other perspectives as equally valid. This finding is consistent with that of Miller (1999, 2008) and Alters and Alters (2001), who contend that a lack of understanding about evolutionary theory is frequently associated with a lack of acceptance and misconceptions of evolution and the nature of science.

The content analysis of the lesson ideas exposed the integration of lab activities, field trips, books, and museums into participants' visions for teaching evolution. Participant integration of a variety of concepts and approaches into their lesson ideas that were not discussed in the tutorials suggested that their prior experiences were salient and were important contributions to their visions for teaching evolution. The influence of prior learning experiences on the participants' plans makes apparent the need for continued research on the effectiveness of curriculum and instruction for preparing teachers to teach evolution concepts.

Overall, my investigation revealed the lesson ideas as an effective method for gathering evidence of preservice teachers' visions for teaching evolution. The resulting data provided empirical evidence of the kinds of misconceptions and perspectives preservice teachers may hold with regard to their visions for teaching evolution and related topics. The data also contained evidence that a rather brief tutorial can influence teachers' perspectives of evolution curriculum and instruction.

\section{Limitations}

There were several limitations of my study. First, my participants were all undergraduate preservice teachers. Their limited college level experience may be an important variable influencing their perspectives for teaching evolution. The examination of the perspectives of graduate level preservice teachers may reveal different outcomes. This is an excellent direction for future research.

A second notable limitation of my study was the manner in which participants interacted with the tutorials. Although tutorial instructions were provided, and participation and time on task were monitored and determined to be consistent, I was not able to control for individual attention to the content and depth of their engagement. A greater effect might be achieved if the content is delivered using different methods, such as face-to-face direct instruction with class discussion that would increase the level of participant engagement. This is an excellent approach to consider in future investigations.

One additional limitation of my study worth noting is the lack of an assessment of the participants' prior knowledge of the concepts associated with the tutorial interventions. This may be seen as a significant flaw of my study, as it is difficult to determine exactly how much knowledge was transferred from the study interventions. My goal was to gather preservice teachers' visions for teaching evolution and evidence of tutorial influence; therefore, I determined that prior knowledge was not as critical to my study objective. Whether the tutorials activated prior knowledge, resolved or reinforce misconceptions, or stimulated learning, it is apparent that there was some influence. However, because I did not pretest my participants, I cannot quantify the extent of the influence or the nature of the effect, which are important considerations for subsequent research.

It is encouraging that evidence was found for the effectiveness of a brief instructional intervention on preservice teachers' visions for teaching evolution. Continued research is needed to determine the most effective ways of increasing preservice teachers' knowledge of evolution and their ability to integrate instructional content into meaningful science lessons. The persistence of misconceptions and the ramification of possible perpetuation suggest greater attention needs to be paid to preservice teacher knowledge of evolution, the nature of 
science, and situations of chance prior to entering the profession.

\section{Appendix 1}

Tutorial Screen Captures

\section{Misconceptions}

Misconceptions About Evolution and the Mechanisms of Evolution

Unfortunately, people have misconceptions about evolution. Some are simple misunderstandings; ideas that develop in the course of learning about evolution, possibly from school experiences and/or from the media. Other misconceptions may stem from purposeful attempts to interfere with the teaching of evolution.

As teachers, it is our role to treat all student questions with respect and initially to accept each question as the reflection of a legitimate desire to learn. However, some questions may well be designed to disrupt the learning process. We need to deal with intentionally disruptive questions in ways that are a bit different from legitimate inquiry, and it is important that we learn to distinguish between the two.

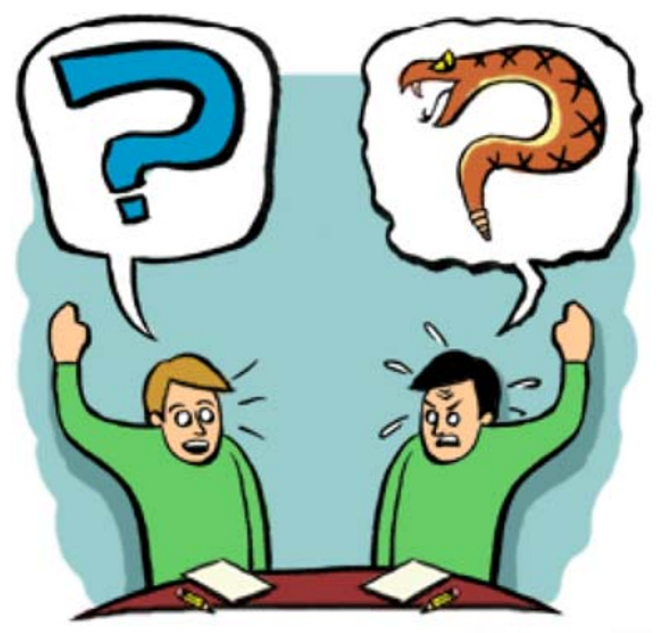

\section{Nature of Science}

Understanding how science works allows one to easily distinguish science from non-science. Thus, to understand biological evolution, or any other science, it is essential to begin with the nature of science.

What is Science?

Science is a particular way of understanding the natural world. It extends the intrinsic curiosity with which we are born. It allows us to connect the past with the present, as with the redwoods depicted here.

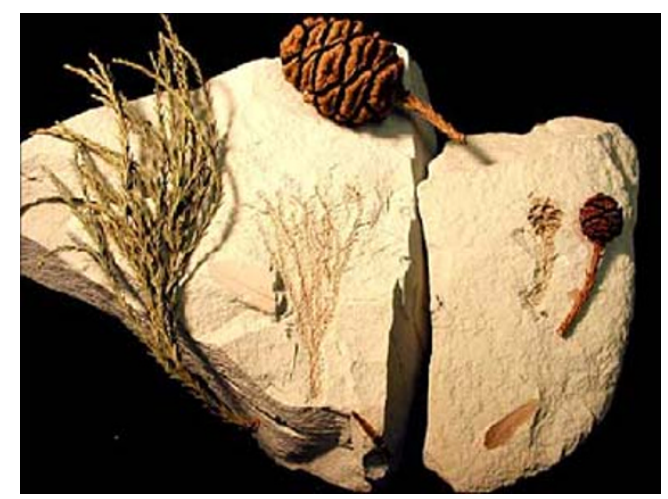

Science is based on the premise that our senses, and extensions of those senses, through the use of instruments, can give us accurate information about the Universe. Science follows very specific "rules," and its results are always subject to testing and, if necessary, revision. Even with such constraints, science does not exclude, and often benefits from, creativity and imagination (with a good bit of logic thrown in).

\section{Situations of Uncertainty}

Bridging Biological Evolution and Chance

\section{Introduction}

The process of evolution is of random events. It is a common misconception that somehow animals or plant "think" that some sort of trait or mutation would be beneficial, and therefore, it is selected for. This is not correct. Evolution is a random process with mutations and natural selection occurring in no particular direction but just happening. Over time, mutation can give rise to new species, but there is no drive for species to move in one particular direction; it just happens. This is perhaps the greatest misconception of evolution, that somehow there is a deterministic push toward some sort of "super species." This is NOT how evolution functions. Evolution is the result of random events that take place over time that can result in different species. There is NO goal or product to reach.

The following is intended to teach you more about random processes. It is hypothesized that many people do not understand evolution because they do not understand random events and situations of uncertainty. However, if you gain a greater understanding of random events (situations of uncertain outcome), you are more likely to understand the processes of evolution. 


\section{The Random Events of Evolution}

Given the random nature of evolution, it is perhaps helpful to examine the relationship of species variation and chance occurrence. This is displayed below with an animation to help you imagine the chance occurrence of species variation.

\begin{tabular}{|l|l|}
\hline [APPLET] \\
\hline $\begin{array}{l}\text { Distribution of beak pigment }- \text { a } \\
\text { randomly expressed trait with the } \\
\text { majority falling in the center, and } \\
\text { then some lighter and darker beaks } \\
\text { occurring with less frequency on the } \\
\text { sides. Therefore, most birds of this } \\
\text { type have tan beaks, but some will } \\
\text { be nearly white while others are } \\
\text { brown, but these are not as common. }\end{array}$
\end{tabular} $\begin{aligned} & \begin{array}{l}\text { The outcome of a random } \\
\text { distribution of possible outcomes. } \\
\text { Notice the most likely outcome is in } \\
\text { the center. Applying this model to } \\
\text { biological traits means that the } \\
\text { random variation of traits is most } \\
\text { likely to show up in the middle of a } \\
\text { distribution. Thus, light and dark } \\
\text { beaks or short and long beaks still } \\
\text { happen but not as often as tan and } \\
\text { medium length beaks. }\end{array} \\
& \begin{array}{l}\text { Beak } \\
\text { protein that all bird have. But } \\
\text { because of random variation some } \\
\text { birds will randomly express more or } \\
\text { less. This is similar to growth } \\
\text { hormone in humans resulting in } \\
\text { different heights. }\end{array}\end{aligned}$

\section{Voyage of the Beagle}

The Journey

The Voyage of the Beagle is a title commonly given to the book written by Charles Darwin published in 1839 as his Journal and Remarks, which brought him considerable fame and respect. The title refers to the second survey expedition of the ship HMS Beagle, which set out on 27 December 1831 under the command of captain Robert FitzRoy.

The Expedition

While the expedition was originally planned to last 2 years, it lasted almost five - the Beagle did not return until 2

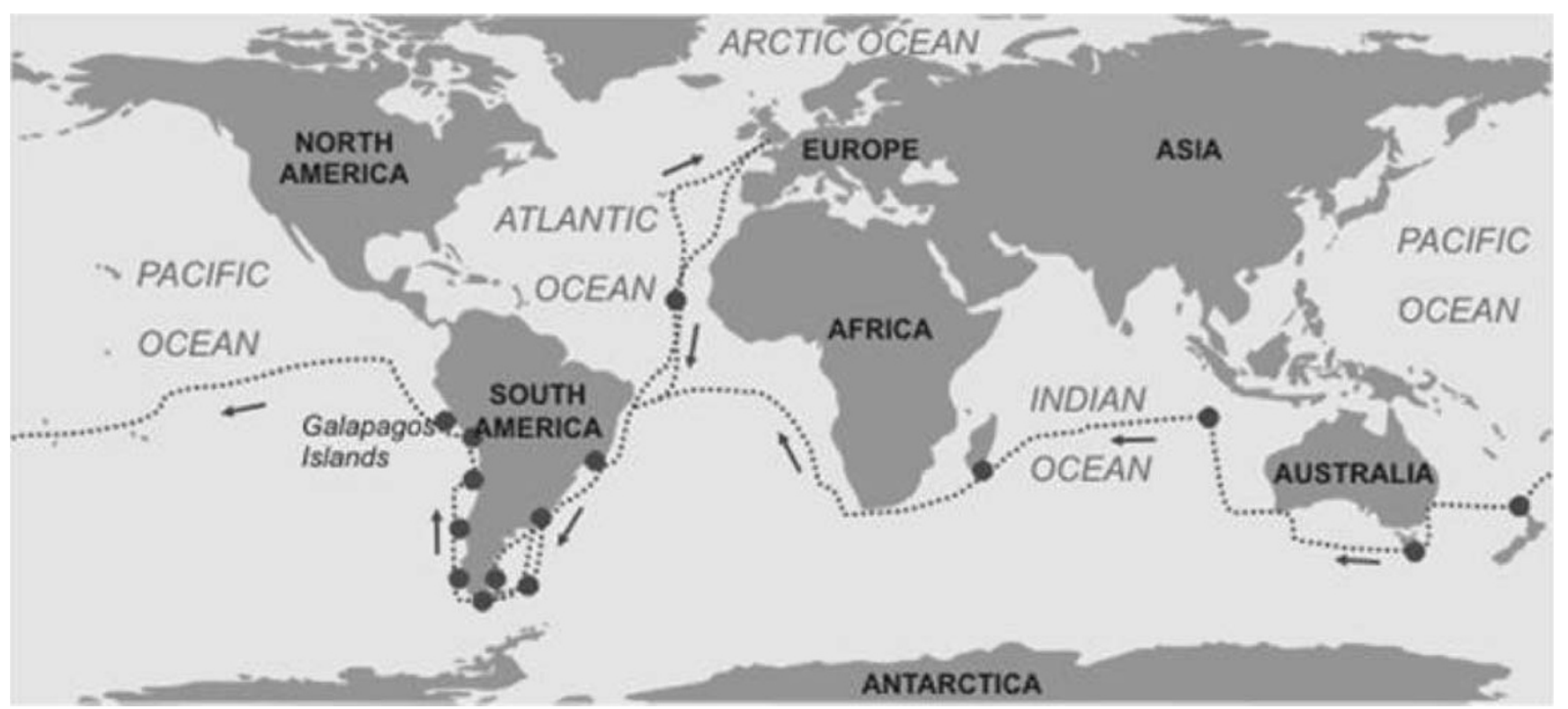


October 1836. Darwin spent most of this time exploring on land (3 years and 3 months on land; 18 months at sea).

The map of the voyage of the Beagle.

The book, also known as Darwin's Journal of Researches, is a vivid and exciting travel memoir as well as a detailed scientific field journal covering biology, geology, and anthropology that demonstrates Darwin's keen powers of observation, written at a time when Western Europeans were still discovering and exploring much of the rest of the world. Although Darwin revisited some areas during the expedition, for clarity, the chapters of the book are ordered by reference to places and locations rather than chronologically. With hindsight, ideas which Darwin would later develop into the theory of evolution are hinted at in the book.

\section{Appendix 2}

\section{Lesson Idea Template}

Instructions: Based on your experience and the knowledge you have gained navigating through the tutorials, create a lesson idea related to biological evolution. This lesson idea should target the students you intend to teach. Please complete each part of this template and hold your response to 1 page.

Title of Activity
Grade Level
Content/Subject Area
Lesson Goals:
Description of Lesson Activities:
Assessment Plan:

\section{References}

Abd-El-Khalick F, Akerson VL. Learning as conceptual change: factors mediating the development of preservice elementary teachers' views of nature of science. Sci Educ 2004;88(5):785810. doi:10.1002/sce.10143.

Alters BJ. Teaching biological evolution in higher education: methodological, religious, and nonreligious issues. Boston: Jones and Bartlett; 2004.

Alters BJ, Alters SM. Defending evolution: a guide to the creation/ evolution controversy. Sudbury, MA: Jones \& Bartlett; 2001.

Alters BJ, Nelson CE. Perspective: teaching evolution in higher education. Evolution Int J Org Evolution 2002;56:1891-901.

American Association for the Advancement of Science. Benchmarks for science literacy. New York: Oxford University Press; 1993.

Chinn M, Brewer W. An empirical test of a taxonomy of responses to anomalous data in science. J Res Sci Teach 1998;35(6):623-54. doi:10.1002/(SICI)1098-2736(199808)35:6<623::AIDTEA3>3.0.CO;2-O.
Cooper RA. Scientific knowledge of the past is possible: confronting myths about evolution \& scientific methods. Am Biol Teach 2002;64(6):427-32. doi:10.1662/0002-7685(2002)064[0427: SKOTPI]2.0.CO;2.

Crawford BA, Zembal-Saul C, Munford D, Friedrichsen P. Confronting prospective teachers' ideas of evolution and scientific inquiry using technology and inquiry-based tasks. J Res Sci Teach 2005;42(6):613-37. doi:10.1002/tea.20070.

Cresswell JW. Research design: qualitative, quantitative, and mixed methods approaches, 2nd edn. Thousand Oaks, CA: Sage Publications, Inc; 2003.

Dagher ZR, Boujaoude S. Students' perceptions of the nature of evolutionary theory. Sci Educ 2005;89(3):378-91. doi:10.1002/ sce. 20054 .

Darling-Hammond L, Bransford J, editors. (2005). Preparing teachers for a changing world: What teachers should learn and be able to do. San Francisco, CA: Jossey-Bass.

Dawkins R. The blind watchmaker: why the evidence of evolution reveals a universe without design. New York: Norton; 1986.

Deemer S. Classroom goal orientation in thigh school classrooms: revealing links between teacher beliefs and classroom environments. Educ Res 2004;46(1):73-90. doi:10.1080/0013188042000178836.

Dobzhansky T. Nothing in biology makes sense except in the light of evolution. Am Biol Teach 1973;35:125-9.

Driver R, Squires A, Rushworth P, Wood-Robinson V. Making sense of secondary science. New York, NY: Routledge; 1994.

Evans EM. Cognitive and contextual factors in the emergence of diverse belief systems: Creation versus evolution. Cognit Psychol 2001;42(3):217-66. doi:10.1006/cogp.2001.0749.

Fisher KM. The importance of prior knowledge in college science instruction. In: Dunal DW, Wright EL, Day JB, editors. Reform in Undergraduate Science Teaching for the 21st Century. Greenwich, CT: Information Age Publishing; 2004. p. 69-83.

Florida State Department of Education (FLDOE). Sunshine State Science Standards. Tallahassee, FL: Florida Department of Education; 2008.

Futuyma D. Natural selection: How evolution works. Retrieved February 5, 2008, from http://www.actionbioscience.org/evolution/futuyma.html; 2002.

Gallup G. (2008). Evolution, creationism and intelligent design. Retrieved October 25, 2008, from http:/www.gallup.com/poll/ 21814/Evolution-Creationism-Intelligent-Design.aspx.

Garvin-Doxas K, Klymkowsky MW. Understanding randomness and its impact on student learning: lessons learned from building the biology concept inventory. CBE Life Sci Educ 2008;7(2):22733. doi:10.1187/cbe.07-08-0063.

Gould SJ. The structure of evolutionary theory. Cambridge, MA: Harvard University Press; 2002.

Haidar AH. Prospective chemistry teachers' conceptions of the conservation of matter and related concepts. J Res Sci Teach 1997;34(2):181-97. doi:10.1002/(SICI)1098-2736(199702) 34:2<181::AID-TEA5>3.0.CO;2-P.

Hill L. Changing minds: developmental education for conceptual change. J Adult Dev 2004;11(1):29-40. doi:10.1023/B:JADE. 0000012525.69639.5d.

Hoy A, Davis H, Pape SJ. Teacher knowledge and beliefs. In: Alexander PA, Winne PH, editors. Handbook of educational psychology. 2nd ed. Mahwah, NJ: Lawrence Erlbaum; 2006. p. 715-37.

Jarvis T, Pell A, McKeon F. Changes in primary teachers' science knowledge and understanding during a two year in-service programme. Res Sci Technol Educ 2003;21(1):17-42. doi:10. 1080/02635140308341.

Kikas E. Teachers' conceptions and misconceptions concerning three natural phenomena. J Res Sci Teach 2004;41(5):432-48. doi:10.1002/tea.20012. 
Lawrenz F. Misconceptions of physical science concepts among elementary school teachers. Sch Sci Math 1986;86(8):654-60.

Llinares S, Krainer K. Mathematics (student) teachers and teacher educators as learners. In: Gutierrez A, Boero P, editors. Handbook of research on the psychology of mathematics education. Rotterdam, The Netherlands: Sense Publishers B.V.; 2006.

Mazur A. Believers and disbelievers in evolution. Politics Life Sci 2004;23(2):55-61. doi:10.2990/1471-5457(2004)23[55:BADIE] 2.0.CO;2.

McComas WF. The nature of science in science education rationales and strategies. Boston: Kluwer Academic Publishers; 1998.

McComas WF. Investigating evolutionary biology in the laboratory. Dubuque, WI: Kendall/Hunt Publishing Company; 2006.

Miles MB, Huberman AM. Qualitative data analysis: an expanded sourcebook. 2nd ed. Thousand Oaks, CA: Sage; 1994.

Miller KR. Finding Darwin's God: a scientist's search for common ground between God and evolution. New York: Cliff Street Books, HarperCollins; 1999.

Miller KR. Only a theory: evolution and the battle for America's soul. New York: Viking Press; 2008.

Moore R. Teaching evolution: do state standards matter? Rep Natl Cent Sci Educ 2001;21(1-2):19-21.

National Academy of Sciences. Teaching about evolution and the nature of science. Washington, DC: National Academy Press; 1998.

National Academy of Sciences. Science, evolution and creationism. Washington, DC: National Academy Press; 2008.

National Research Council. National science education standards. Washington, DC: National Academy Press; 1996.

National Research Council. Taking science to school: learning and teaching science in grades K-8. Washington, DC: National Academy Press; 2007.

National Science Teachers Association. An NSTA position statement on the teaching of evolution. J Coll Sci Teach. 1997;27(1):7-8.

Nickerson R. Cognition and chance, the psychology of probabilistic reasoning. Mahwah, NJ: Lawrence Erlbaum Associates; 2004.
Pajares MF. Teachers' beliefs and educational research: cleaning up a messy construct. Rev Educ Res 1992;62(3):307-32.

Palmquist BC, Finley FN. Preservice teachers' views of the nature of science during a postbaccalaureate science teaching program. J Res Sci Teach 1997;34(6):595-615. doi:10.1002/(SICI)10982736(199708)34:6<595::AID-TEA4>3.0.CO;2-I.

Sadler TD. Evolutionary theory as a guide to socioscientific decisionmaking. J Biol Educ 2005;39(2):68-72.

Scharmann LC, Smith MU, James MC, Jensen M. Explicit reflective nature of science instruction: Evolution, intelligent design, and umbrellaology. J Sci Teach Educ 2005;16(1):27-41. doi:10.1007/ s10972-005-6990-y.

Shaughnessy J. Research on students' understanding of probability. In: Kilpatrick J, Martin WG, Schifter D, editors. A research companion to principles and standards for school mathematics. Reston, VA: NCTM; 2003. p. 216-26.

Shulman L. Knowledge and teaching: Foundations of the new reform. Harv Educ Rev 1987;57(1):1-22.

Sinatra GA, Southerland SA, McConaughy F, Demastes JW. Intentions and beliefs in students' understanding and acceptance of biological evolution. J Res Sci Teach 2003;40:510-28. doi:10.1002/tea.10087.

Tversky A, Kahneman D. Judgment under uncertainty, heuristics and biases. In: Kahneman D, Slovic P, Tversky A, editors. Judgment under uncertainty, heuristics and biases. New York: Cambridge University Press; 1982. p. 3-21.

University of California Museum of Paleontology. (2006, October). Understanding evolution. Retrieved October 3, 2006, from The University of California Museum of Paleontology, Berkeley, and the Regents of the University of California. Web site: http:// evolution.berkely.edu.

Vosniadou S. Exploring the relationships between conceptual change and intentional learning. In: Sinatra GM, Pintrich R, editors. Intentional conceptual change. Mahwah, NJ: Lawrence Erlbaum Associates; 2003. p. 377-406.

Wolpert L. Six impossible things before breakfast: the evolutionary origins of belief. London: Faber and Faber; 2007. 